\title{
Brominated Flame Retardants - Endocrine-Disrupting Chemicals in the Swiss Environment
}

\author{
Andreas C. Gerecke ${ }^{\star a}$, Peter Schmid ${ }^{\mathrm{a}}$, Christian Bogdal ${ }^{\mathrm{a}}$, Martin Kohler ${ }^{\mathrm{ab}}$, Markus Zennegg $^{\mathrm{a}}$, \\ and Norbert V. Heeb ${ }^{a}$
}

\begin{abstract}
Brominated flame retardants (BFR) are additives used to protect plastic materials and textiles against ignition. As some widely used BFR have chemical structures similar to well known endocrine disruptors such as polychlorinated biphenyls (PCB) or bisphenol A, adverse effects were also presumed for BFR. When the NRP50 programme started in 2001, the sparse knowledge on environmental behavior and toxicology of BFR did not allow a proper assessment of the risks associated with the widespread use of these chemicals. Therefore, we proposed to address questions such as the exposure of animals and humans, temporal trends in the environment as well as transformation and transport processes of BFR. Concentrations of BFR in wildlife and humans in Switzerland today pose no serious concerns for negative health effects according to the current knowledge on the toxicity of BFR. However, negative health effects cannot be ruled out in the future, since some BFR persist in the environment and their concentrations in freshwater lake sediments are increasing rapidly. The development of environmentally safe alternatives to these chemicals will be an important issue for the future.
\end{abstract}

Keywords: Brominated flame retardants · Emerging contaminants · Endocrine disruptors .

Persistent organic pollutants

\section{Introduction}

The first chemicals known to interfere with the hormone system of humans and wildlife (endocrine disruptors) include polyhalogenated organic compounds such as the insecticide DDT (dichlorodiphenyl-trichloroethane) and PCB (polychlorinated biphe-

\footnotetext{
${ }^{\star}$ Correspondence: Dr. A. C. Gerecke ${ }^{a}$

Tel.: +41448234653

Fax: + 41448235614

E-mail: andreas.gerecke@empa.ch

aEmpa, Swiss Federal Laboratory for Materials,

Testing, and Research

Laboratory for Analytical Chemistry

Überlandstrasse 129

$\mathrm{CH}-8600$ Dübendor

bpresent address:

Kanton Solothurn Lebensmittelkontrolle

Werkhofstrasse 5

$\mathrm{CH}-4509$ Solothurn
}

nyls), chemicals used as transformer oils or plasticizers. When the NRP50 programme was initiated, first in vitro-based data on endocrine disruption caused by brominated flame retardants (BFR) were available. BFR are chemicals used to protect plastic materials and textiles against easy ignition. Electric and electronic equipment, textiles and building materials are the most important applications for BFR. BFR are mostly used as additives for polymeric materials, however, some BFR, including tetrabromobisphenol A (TBBPA), are chemically bound to the polymeric structure. The estimated annual global market demand for BFR exceeds 200,000 tonnes, rendering BFR an important class of plastic additives. ${ }^{[1]} \mathrm{BFR}$ represent also the most important current use of bromine. ${ }^{[1]}$ More than fifty different BFR are commercially available, ${ }^{[2]}$ however, at the beginning of the NRP50 programme, the market was dominated by four commercial products, which we selected as our target chemicals (Table 1): TBBPA, decabromodiphenyl ether (DecaBDE), hexabromocyclododecane (HBCD), and pentabromodiphenyl ether (PentaBDE). At that time, about 120,000 tonnes of TBBPA, 56,000 tonnes of DecaBDE, 17,000tonnes of HBCD and 7,500 tonnes of PentaBDE were sold annually. ${ }^{[3]}$
While TBBPA and DecaBDE are single substances, PentaBDE consists of a mixture of tri- to heptabromodiphenylethers, ${ }^{[4]}$ and HBCD is a mixture of stereoisomers of 1,2,5,6,9,10-hexabromocyclododecane..$^{[5-8]}$ Within this paper, we will restrict our discussion to the sum of the major components of PentaBDE and HBCD. This is well justified for PentaBDE, where we found only minor changes between the congener patterns of the commercial product and environmental residues. However, this is a simplification for HBCD, where isomer patterns strongly differ between the commercial product and environmental residues. ${ }^{[9,10]}$

The toxicological database and the knowledge on the environmental chemistry of BFR were scanty in 2001, making a sound risk-benefit assessment impossible. Therefore, we decided to address key questions aimed at the risk analysis of BFR, such as the occurrence of BFR in the environment, the identification of temporal trends of environmental BFR concentrations as well as the identification of major transport and transformation processes of these chemicals. The main part of our research on BFR was performed within three individual NRP50 research projects, carried out at Empa with partners at Eawag, ETHZ, 
Table 1. Chemical structures and main use of the most important brominated flame retardants.

\section{Flame retardant}

Polybrominated diphenylethers (PBDE) (209 congeners)

technical products:

PentaBDE: $x+y=3-7$

DecaBDE: $x=y=5$

Hexabromocyclododecane (HBCD)

(16 stereoisomers)

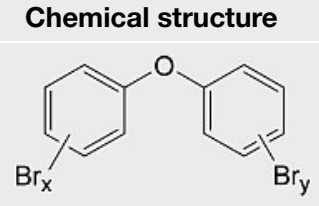

\section{Main use}

additive flame retardant in polymers for fabrics furniture, and electronics

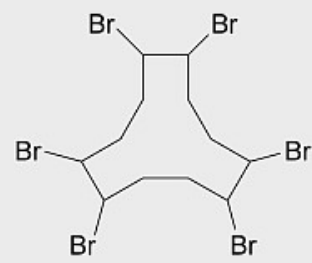

additive flame retardant in polystyrene foams

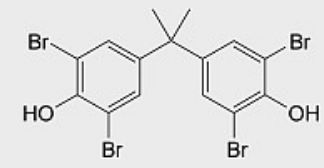

reactive flame retardant in epoxy resins

Tetrabromobisphenol A (TBBPA)

Table 2. Overview on research activities on brominated flame retardants at Empa within NRP50 and other projects

\section{Research question \\ Analytical chemistry of BFR}

Exposure of human and wildlife to BFR

Concentration of BFR in abiotic media

Temporal trends

Transport and transformation

\section{Activities}

- development of trace analytical methods for PentaBDE, DecaBDE, HBCD and TBBPA in biological and abiotic samples (clean-up methods followed by analysis by GC/ MS and LC/MS)

- determination of crystal structures of stereoisomers of 1,2,5,6,9,10-hexabromocyclododecanes present in technical HBCD

analysis of muscle tissue of whitefish from plateau lakes, muscle tissue of whitefish from Lake Thun, muscle tissue of brown trout in waste water impacted rivers, muscle tissue of fish from alpine lakes, liver fat of urban foxes, human breast milk

analysis of air samples (gas and particulate phase), atmospheric deposition samples, home and office dust samples, water samples, sewage sludge, compost, lake sediments

- analysis of BFR in dated sediment cores

- analysis of BFR in current and archived sewage sludge

- regional mass balance of BFR in Lake Thun area

- multimedia computer model of mass transfer processes in Lake Thun area

- biologically mediated degradation of DecaBDE, TBBPA and HBCD in anaerobic sewage sludge

- photodegradation of DecaBDE on model soil surfaces
Refs. the University of Zurich, the University of Bern, and the Canton of Bern.

In this article, we will summarize results of our NRP50 projects (Table 2) and combine them with other studies on the occurrence, fate and transport of BFR in Switzerland. The aggregated data are used to identify sources of BFR and discuss the impact of BFR on humans and the environment in Switzerland. We have focussed specially on the discussion of potential endocrine effects of BFR on the basis of the current toxicological database. This database has substantially improved the knowledge of endocrine, neurotoxic and other biological effects.

\section{BFR in Fish and Other Biological Samples}

Over the past seven years, we collected and analyzed a large number of samples, originating from the aquatic, terrestrial and atmospheric environment (Table 3). Fish are known to accumulate lipophilic persistent compounds. Therefore, they represent a suitable indicator for the pollution of their aquatic environment with BFR. The most illustrative data are concentrations of BFR in fish samples from multiple locations, worldwide (Fig. 1 and 2). Data on BFR concentrations in fish have recently become available glob- ally, enabling comparisons with known hot-spots near industrial sources and with pristine regions without direct anthropogenic input.

In a first study, we analyzed PentaBDE, DecaBDE, HBCD and TBBPA in muscle tissue of whitefish (Coregonus sp.) from ten lakes of the Swiss plateau..$^{[9,11]}$ Whereas DecaBDE and TBBPA could not be detected, PentaBDE and HBCD were found in all samples at concentrations ranging from 36-165 and from 25-210 ng/g lipid weight, respectively. This narrow range between lowest and highest residues are a first indication that in Switzerland environmental contamination with PentaBDE or HBCD originates from multiple diffuse sources and is not caused by a small number of point sources. Contamination by major point sources would result in much larger concentration ranges. This is corroborated by the detection of PentaBDE and HBCD in brown trout caught in ten small rivers downstreams of municipal wastewater treatment plants without major industrial discharge (Table 3 ). In the very dry summer of 2003, all these rivers were heavily impacted by effluents of the municipal wastewater treatment plants, and these samples represent a worst case scenario with respect to low dilution of the effluent with river water. The concentrations of PentaBDE and HBCD indicate that ordinary municipal wastewater treatment plants and combined sewer overflows are a source of PentaBDE and HBCD. On the other hand, PentaBDE and HBCD were also detected in fish from remote alpine lakes. ${ }^{[12]}$ Concentrations were slightly lower than in the whitefish from the plateau lakes. Therefore, it became clear that the atmosphere is also a major transport medium for BFR from their sources into the environment.

PentaBDE and HBCD concentrations in Swiss lake fish are more than ten times lower than concentrations near known industrial point sources such as plants producing or processing BFR (Fig. 1 and 2), which corroborates our assumption that there are no major point sources of PentaBDE and HBCD in Switzerland. PentaBDE concentrations in Switzerland are also lower than in North America, which is likely due to the higher use of PentaBDE in North America. [26] On the other hand, PentaBDE concentrations in fish from many European rivers and lakes are in the same order of magnitude as in Switzerland. As shown in Fig. 2, concentrations of HBCD in European fish are also comparable to the concentrations we found in Switzerland, with the exception of fish sampled close to known production sites of HBCD. ${ }^{[10]}$. In addition to fish, we collected also data on BFR in urban foxes. ${ }^{[13]}$ Naert $e t$ al. ${ }^{[20]}$ published data on PentaBDE in Swiss birds (Table 3 ). For both species, concentra- 
Table 3. Overview of concentrations of key brominated flame retardants in wildlife, human and abiotic samples from Switzerland

\begin{tabular}{|c|c|c|c|c|c|c|c|c|}
\hline \multirow[t]{2}{*}{ Sample } & & \multirow[t]{2}{*}{ Units } & \multirow{2}{*}{$\begin{array}{c}\text { Number } \\
\text { of } \\
\text { samples } \\
\text { (n) }\end{array}$} & \multicolumn{4}{|c|}{$\begin{array}{l}\text { Concentration } \\
\text { mean } \\
\text { (min-max) }\end{array}$} & \multirow[t]{2}{*}{ Refs. } \\
\hline & & & & PentaBDE & DecaBDE & HBCD & TBBPA & \\
\hline \multirow[t]{4}{*}{ Fish } & $\begin{array}{l}\text { Whitefisha } \\
\text { muscle tissue } \\
\text { (plateau lakes) }\end{array}$ & $\mathrm{ng} / \mathrm{g}$ Iw & $6-10^{b}$ & $\begin{array}{c}89 \\
(36-165)\end{array}$ & $<10$ & $\begin{array}{c}95 \\
(25-210)\end{array}$ & $<10$ & {$[9,11]$} \\
\hline & $\begin{array}{l}\text { Brown trout }^{\mathrm{a}} \\
\text { muscle tissue } \\
\text { (waste water impacted rivers) }\end{array}$ & $\mathrm{ng} / \mathrm{g}$ Iw & 25 & $\begin{array}{c}670 \\
(140-1300)\end{array}$ & $<10$ & $\begin{array}{c}120 \\
(44-250)\end{array}$ & n.a. & unp. \\
\hline & $\begin{array}{l}\text { Brown trout } \\
\text { liver } \\
\text { (small rivers) }\end{array}$ & $\mathrm{ng} / \mathrm{g}$ Iw & $11^{d}$ & $(16-7400)$ & n.a. & n.a. & n.a. & {$[18]$} \\
\hline & $\begin{array}{l}\text { Multiple species }^{a} \\
\text { muscle tissue } \\
\text { (remote alpine lakes) }\end{array}$ & $\mathrm{ng} / \mathrm{g}$ Iw & $7^{e}$ & $(13-107)$ & n.a. & $(<10-36)$ & n.a. & {$[12,19]$} \\
\hline \multirow[t]{2}{*}{ Other biota } & $\begin{array}{l}\text { Urban foxes } \\
\text { liver }\end{array}$ & $\mathrm{ng} / \mathrm{g}$ Iw & 3 & $\begin{array}{c}2.4 \\
(1.8-3.7)\end{array}$ & n.a. & $(<0.14-2.3)$ & n.a. & [13] \\
\hline & $\begin{array}{l}\text { Bird species }{ }^{c} \\
\text { adipose tissue }\end{array}$ & $\mathrm{ng} / \mathrm{g}$ ww & 46 & $\begin{array}{c}190 \\
(<L O D-1700)\end{array}$ & n.a. & n.a. & n.a. & {$[20]$} \\
\hline Human & Human breast milka & $\mathrm{ng} / \mathrm{g}$ Iw & 36 & $(2.2-17)$ & $(<0.9-11)$ & $(<0.026-2.3)$ & n.a. & unp. \\
\hline \multirow[t]{4}{*}{ Anthroposphere } & House and office dust ${ }^{a}$ & $\mathrm{ng} / \mathrm{g} d \mathrm{w}$ & 3 & $\begin{array}{c}250 \\
(24-700)\end{array}$ & $\begin{array}{c}300 \\
(200-450)\end{array}$ & $\begin{array}{c}1100 \\
(800-1400)\end{array}$ & n.a. & unp. \\
\hline & $\begin{array}{l}\text { Sewage sludge } \\
\text { (Zürich area) }\end{array}$ & $\mathrm{ng} / \mathrm{g} d \mathrm{w}$ & 8 & $\begin{array}{c}70 \\
(30-100)\end{array}$ & $\begin{array}{c}1100 \\
(220-1700)\end{array}$ & $\begin{array}{c}25 \\
(n=1)\end{array}$ & $\begin{array}{c}6 \\
(n=1)\end{array}$ & {$[15,21]$} \\
\hline & Compost samples ${ }^{f}$ & $\mathrm{ng} / \mathrm{g} \mathrm{dw}$ & 18 & $\begin{array}{c}2.0 \\
(0.18-4.4)\end{array}$ & $\begin{array}{c}8.4 \\
(0.55-31)\end{array}$ & $\begin{array}{c}110 \\
(17-370)\end{array}$ & $\begin{array}{c}0.67 \\
(0.065-2.0)\end{array}$ & [22] \\
\hline & Sewage sludge ${ }^{c}$ & $\mathrm{ng} / \mathrm{g} d \mathrm{w}$ & 16 & $\begin{array}{c}95 \\
(50-250)\end{array}$ & $\begin{array}{c}310 \\
(140-620)\end{array}$ & $\begin{array}{c}150 \\
(40-600)\end{array}$ & n.a. & [23] \\
\hline \multirow[t]{2}{*}{ Hydrosphere } & $\begin{array}{l}\text { Surface lake sediments } \\
\text { (Lake Thun and Greifensee) }\end{array}$ & $\mathrm{ng} / \mathrm{g} d \mathrm{w}$ & 4 & $\begin{array}{c}0.6 \\
(0.2-1.6)\end{array}$ & $\begin{array}{c}2.7 \\
(0.2-7.2)\end{array}$ & $\begin{array}{c}0.9 \\
(0.1-2.5)\end{array}$ & n.a. & [24] \\
\hline & $\begin{array}{l}\text { Water samples }{ }^{a} \\
\text { (Lake Thun) }\end{array}$ & $\mathrm{pg} / \mathrm{l}$ & 2 & $\begin{array}{c}36 \\
(16-55)\end{array}$ & $\begin{array}{c}13 \\
(13-14)\end{array}$ & n.a. & n.a. & {$[24]$} \\
\hline \multirow[t]{2}{*}{ Atmosphere } & $\begin{array}{l}\text { Air samples - gas phase and } \\
\text { particles }^{a} \\
\text { (Lake Thun area) }\end{array}$ & $\mathrm{pg} / \mathrm{m}^{3}$ & 11 & $\begin{array}{c}61 \\
(26-106)\end{array}$ & $\begin{array}{c}4 \\
(0.5-13)\end{array}$ & $\begin{array}{c}34 \\
(14-71)\end{array}$ & n.a. & {$[24]$} \\
\hline & $\begin{array}{l}\text { Atmospheric deposition }{ }^{a} \\
\text { (Lake Thun area) }\end{array}$ & $\mathrm{ng} /\left(\mathrm{m}^{2} \mathrm{~d}\right)$ & $2-4$ & $\begin{array}{c}1.4 \\
(0.6-2.3)\end{array}$ & $\begin{array}{c}2.8 \\
(1.4-4.0)\end{array}$ & $\begin{array}{c}2.4 \\
(1.9-2.8)\end{array}$ & n.a. & [24] \\
\hline
\end{tabular}

aour studies; ${ }^{b}$ pools of 10 fish for every sample; ${ }^{c}$ studies by other Swiss research groups; ${ }^{d}$ pools of $4-29$ fish; ${ }^{e}$ pools of four different fish species from seven lakes; ${ }^{f}$ analysis of BFR within studies of Swiss partners;

$\mathrm{ng} / \mathrm{g}$ Iw = ng/g lipid weight; $\mathrm{ng} / \mathrm{g} w \mathrm{w}=\mathrm{ng} / \mathrm{g}$ wet weight; $\mathrm{ng} / \mathrm{g} \mathrm{dw}=\mathrm{ng} / \mathrm{g}$ dry weight

n.a. = not analyzed, unp. $=$ unpublished

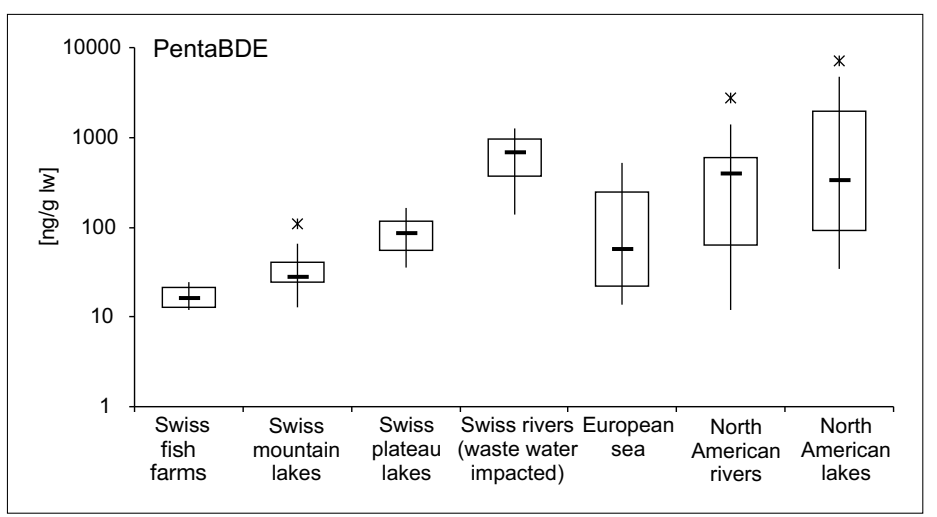

Fig. 1. Concentrations of PentaBDE given in ng/g lipid weight (ng/g Iw) in fish from Swiss fish farms, ${ }^{[11]}$ Swiss mountain lakes, ${ }^{[12]}$ Swiss plateau lakes[11] and Swiss rivers heavily impacted by wastewater (own data, unpublished). For comparison, concentrations in fish from European sea, [25] North American rivers ${ }^{[25]}$ and North American lakes ${ }^{[25]}$ are included.

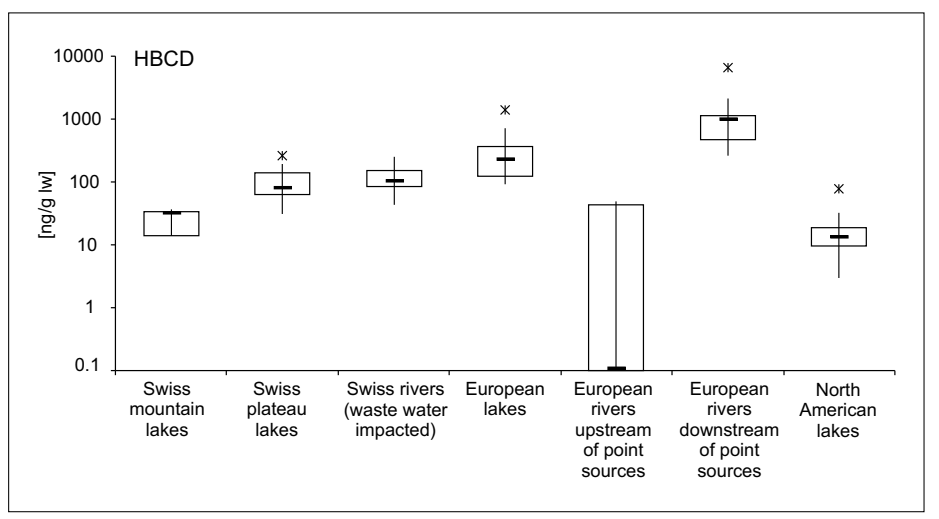

Fig. 2. Concentrations of HBCD given in $\mathrm{ng} / \mathrm{g}$ lipid weight $(\mathrm{ng} / \mathrm{g} \mathrm{lw}$ ) in fish from Swiss mountain lakes, ${ }^{[19]}$ Swiss plateau lakes ${ }^{[9]}$ and Swiss rivers heavily impacted by waste water (own data unpublished). For comparison, concentrations in fish from European lakes, ${ }^{[10]}$ European rivers upstream of point sources, ${ }^{[10]}$ European rivers downstream of point sources ${ }^{[10]}$ and North American lakes ${ }^{[10]}$ are included. 
tions were comparable to other European countries. ${ }^{[25,27]}$

On the basis of Swiss fish data, we conclude that multiple sources contribute to the contamination of fish with PentaBDE and $\mathrm{HBCD}$, and that the atmosphere and surface waters are important transport media. DecaBDE and TBBPA could not be detected in Swiss fish. For TBBPA this was also true for other biological and abiotic samples, whereas DecaBDE was found in different abiotic samples, as we will see below. In general, concentrations of key BFR in Switzerland are comparable to those found in other European countries.

\section{BFR in Abiotic Samples}

Our fish data point towards multiple sources for BFR in the environment, with PentaBDE and HBCD exhibiting the highest concentrations. We will now discuss data from selected abiotic samples from the atmosphere, hydrosphere and anthroposphere (air samples, lake sediments and sewage sludge) to expand and verify our previous conclusions.

Concentrations of PentaBDE, DecaBDE and HBCD in sewage sludge (two independent studies ${ }^{[15,23]}$ on a total of 24 waste water treatment plants) ranged from 30-250 ng/g dry weight, from 140-1700 ng/g dry weight and from 25-600 ng/g dry weight, respectively. TBBPA was only found in one single sample at a much lower concentration (6 ng/g dry weight). ${ }^{[21]}$ In contrast to fish and other biota samples, DecaBDE is the dominating BFR in sewage sludge. This holds also true for lake sediments and atmospheric deposition samples, where DecaBDE turned out to be the dominant BFR, whereas HBCD and PentaBDE concentrations are comparable. DecaBDE is thus dominant in abiotic samples but not present in detectable concentrations in biotic samples. Obviously, DecaBDE is not very bioaccumulative, either because it has a very low bioavailability and/or because it is rapidly eliminated.

\section{Human Exposure to BFR}

So far, only limited data on human exposure to BFR could be collected for the Swiss population. A survey on BFR in human breast milk revealed that exposure to PentaBDE and HBCD in Switzerland was in the same range as in other European countries.[28] International studies suggest that in addition to dietary intake uptake of BFR via house dust and other indoor exposure routes may be important, as well. Food concentrations are assumed to be comparable to other European countries, as evidenced by similar concentrations in biological samples. A small survey on dust concentrations in Switzerland (Table 3) revealed comparable concentrations to European data. ${ }^{[29]}$ Toddlers are particularly exposed to contaminated house dust, because they spend a lot of their time close to the floor, and because they transfer dust from hands to the mouth. Toddlers are estimated to ingest up to $100 \mathrm{mg}$ house dust per day. ${ }^{[30}$ This would result in a daily uptake of about $25 \mathrm{ng}$ of PentaBDE, $30 \mathrm{ng}$ of DecaBDE, and $100 \mathrm{ng}$ of HBCD. For PentaBDE, this corresponds roughly to the estimated daily uptake by adults via food of $35 \mathrm{ng} .{ }^{[31]}$

Occupational exposure may also increase human body burden. This has been demonstrated for workers in the electronic dismantling industry, where BFR containing plastic materials are processed. Furthermore, high amounts of flame-retarded materials are present also in other workplace environments such as aircrafts and trains, which for obvious reasons have to meet very stringent fire security standards. In such environments, dust likely contains abraded particles of flame-proofed materials such as textile fibres, originating from seats, carpets and other textiles. This suspicion could be confirmed by analyses of dust collected in a commercial airplane, where high concentrations of DecaBDE and PentaBDE were observed. ${ }^{[32]}$ Future studies should focus on such workplaces and explore the possibilities to reduce human exposure to BFR, while maintaining high fire safety standards.

\section{Temporal Trends}

In addition to current exposure data, temporal trends of environmental concentrations are a key element for assessing the impact of chemicals. This is especially true for chemicals such as BFR, which have long-lasting life cycles between production and disposal, and for which large reservoirs are building up in the anthroposphere. For such chemicals, the current input into the environment may lag behind the production trend by years or decades. Lake sediments are natural archives, recording the deposition of hydrophobic, non-degradable chemicals. For example, a decreasing deposition of PCB into sediments of Lake Greifensee has been observed since the $1960 \mathrm{~s},{ }^{[33]}$ most likely caused by the phase out and ban of these chemicals. Fig. 3 shows the historical record of BFR concentrations in the sediments of Lake Greifensee.[14] For DecaBDE and HBCD, concentrations started to rise in the mid1970s and are still continuing to increase. The data point towards a further increase in the future, maybe at a reduced rate. As both chemicals are produced and used today, future concentrations are hard to predict.
Buser et al. ${ }^{[34]}$ estimated temporal trends of DecaBDE in freshwater sediments in Switzerland on the basis of a dynamic substance flow model for the Swiss anthroposphere. ${ }^{[35]}$ Buser et al. ${ }^{[34]}$ predicted maximum concentrations in the mid-1990s and declining levels thereafter, mainly owing to technological improvements in waste management. Besides inaccurate assumptions for some model parameters, contributions from foreign emission sources exhibiting different temporal trends or local emission sources around Lake Greifensee may constitute possible reasons for the discrepancy between the model of Buser et al. and actual environmental data. For PentaBDE, concentrations increased until 1995 and remained constant since then. Presumably, this is the consequence of the reduced consumption of PentaBDE in Europe in anticipation of its ban, which was issued in Switzerland in 2005. Similar temporal trends have been observed in three sediment cores from Lake Thun. Our observations in lake sediments were confirmed by a comparison of PentaBDE concentrations in recent sewage sludge with levels in archived sludge from the same treatment plants collected in 2002 and 1993. Concentrations of DecaBDE increased by a factor of five between 1993 and 2002, whereas concentrations of PentaBDE decreased by a factor of two ${ }^{[15]}$ in the same period of time.

\section{Sources and Transport of BFR}

In the preceding paragraphs, we discussed environmental concentrations and temporal trends of BFR. In order to reduce environmental levels, however, knowledge on transport and transformation processes is needed. Levels in biota and abiotic sample material imply atmospheric transport as a major pathway and municipal sewer systems as an important source for input into surface waters. In addition, the fact that PentaBDE concentrations in whitefish from ten lakes of the Swiss plateau correlate positively $\left(r^{2}=0.68\right)$ with the surface area-to-volume ratio of these lakes (Fig. 4) points towards atmospheric deposition on the lake surface as an important input pathway. [11]

To address these questions in more detail, a comprehensive field study on BFR mass flows in the Lake Thun area was started in 2006. This study is based on air samples, atmospheric deposition samples, water samples taken at the inlet and outlet of the lake, at wastewater treatment plants and from the lake itself. Fish and sediment samples from the lake were investigated as well. First data indicate that for PentaBDE and DecaBDE the atmospheric and aquatic input are similar. Sedimentation is the 


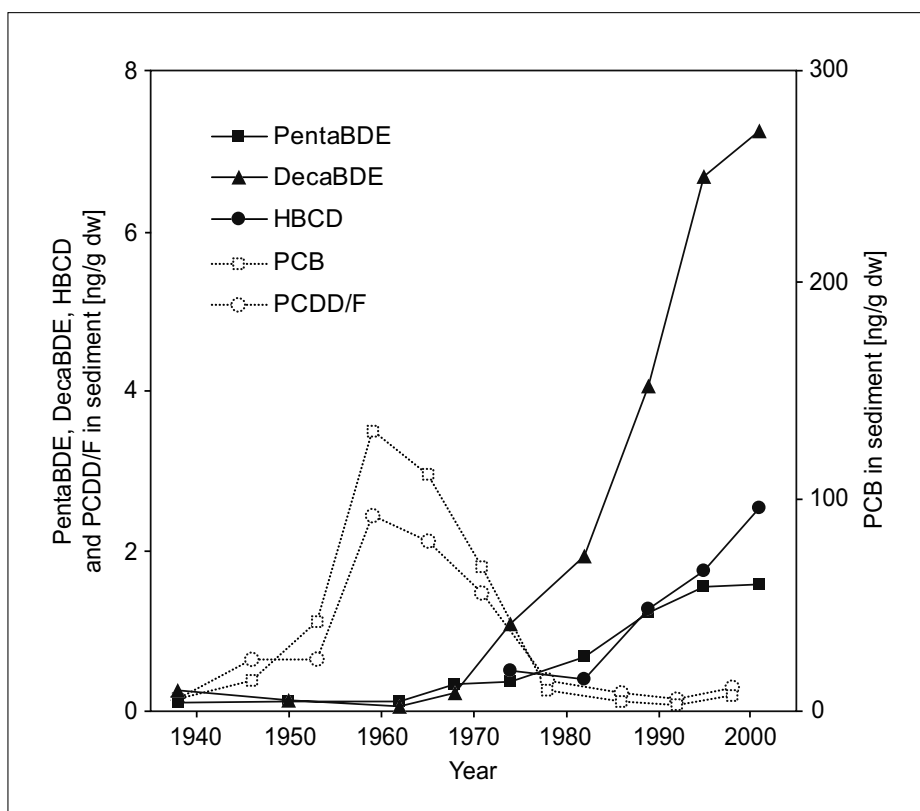

Fig. 3. Concentrations (ng/g dry weight) of PentaBDE, DecaBDE, HBCD, PCB, and polychlorinated-p-dioxin and furans (PCDD/F) in sediments of Lake Greifensee.

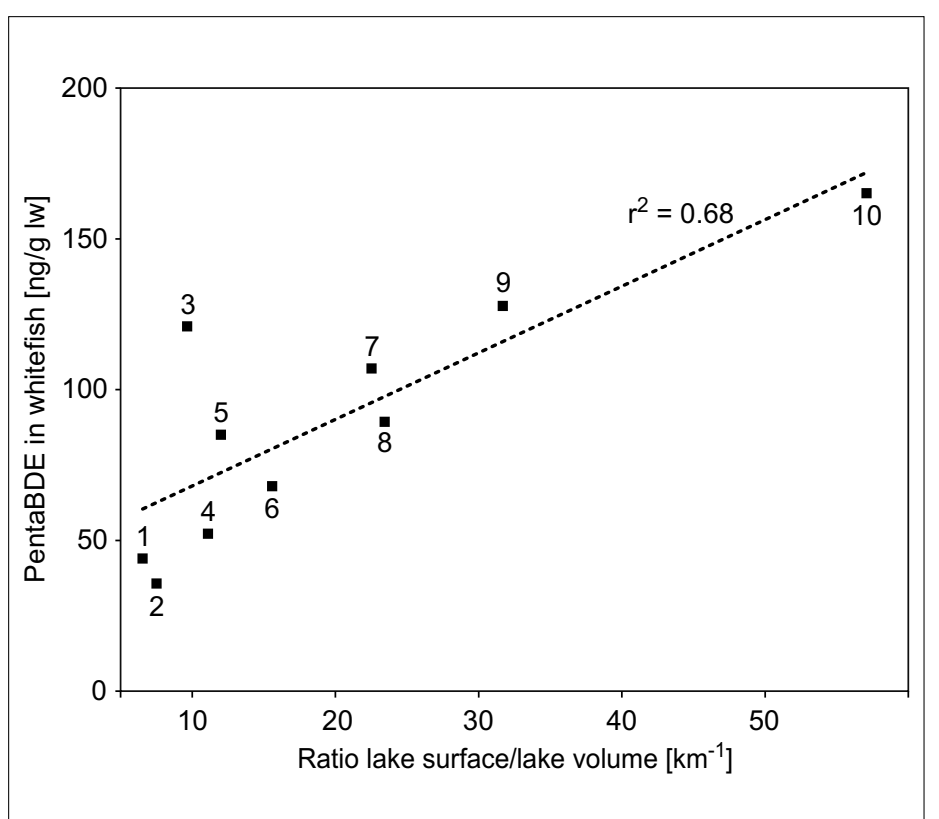

Fig. 4. PentaBDE concentrations ( $\mathrm{ng} / \mathrm{g}$ lipid weight) in whitefish (Coregonus sp.) versus surface/volume $\left(\mathrm{km}^{-1}\right)$ ratios of ten Swiss lakes (1: Lake Geneva, 2: Lake Thun, 3: Lake Lucerne, 4: Lake Constance, 5: Lake Zug, 6: Lake Neuchâtel, 7: Lake Sempach, 8: Lake Zürich, 9: Lake Biel, 10: Lake Greifensee). dominant removal process for DecaBDE whereas for PentaBDE a relevant proportion is also eliminated from Lake Thun through the outflow of the River Aare.

\section{Modelling the Partitioning and the Fate of PBDE on a Local Scale}

To enhance the identification of relevant processes responsible for the transfer of PentaBDE and DecaBDE to the environment, a multimedia mass balance model was tailor-made for Lake Thun as the study ecosystem. The model, which was developed in close collaboration with Martin Scheringer and Konrad Hungerbühler (Swiss Federal Institute of Technology, ETHZ), includes three bulk compartments: atmosphere (consisting of the gaseous phase, fine aerosols and coarse particles), lake water (consisting of the dissolved phase, suspended particles and fish) and bottom sediment (consisting of solid sediment and pore water). Mass balance equations for each compartment were set up, including advective and diffusive transfer processes. Important transformation processes possibly occurring in the environment, such as photodegradation, reaction with atmospheric $\mathrm{OH}$ radicals and biodegradation were considered as well. Measured concentrations in the atmosphere and in tributary rivers served to define the input of these chemicals into Lake Thun. Steady-state calculations, assuming constant PentaBDE and DecaBDE input, enabled the verification of the measured concentrations in the water and sedi- ment compartment. Considering the model uncertainty, the calculated concentrations were close to the measured levels. Calculations showed that the atmosphere is a relevant input pathway for PentaBDE and DecaBDE into Lake Thun and that water and sediment compartments represent the main inventories of these chemicals. Finally, a large proportion of these compounds is buried in sediments. Accumulation in sediments, representing a final sink, was particularly observed for DecaBDE.

In a second step, different scenarios of future PentaBDE and DecaBDE usage were investigated by dynamic modeling. For instance, an immediate stop of input of PentaBDE and DecaBDE into Lake Thun would result in a residual mass of $10 \%$ in the active compartments of Lake Thun after a decade. The remaining $90 \%$ would be partially degraded and to a major extent buried in deep sediments.

In a further study, the model could also be extended to other existing or newly developed chemicals. Thus, it is an effective and complementary tool to the complex and demanding direct measurements of chemicals in the environment, providing valuable contributions to a comprehensive risk assessment.

\section{Environmental Transformation of DecaBDE}

Transformation processes often reduce the overall environmental threat of a toxic compound by a reduction of its concentration and a simultaneous formation of less toxic products. In contrast, for DecaBDE the formation of harmful transformation products has been observed in photodegradation experiments in organic liquids ${ }^{[36]}$ and has been supposed for microbial degradation. Therefore, we decided to study these processes in more detail. In collaboration with our partners from Eawag, we were able to show for the first time that DecaBDE undergoes microbially mediated transformation under anaerobic conditions. ${ }^{[16]}$ Our study in digested sewage sludge revealed a slow transformation of DecaBDE into nona- and octabromodiphenyl ethers, which are known to possess more harmful properties than the precursor DecaBDE.

Within our photodegradation studies, we focused on the transformation of DecaBDE on kaolinite as a model soil mineral. Upon exposure of very thin layers (micrometer range) of DecaBDE to artificial and real sunlight, rapid degradation was observed.[17] The observed half-life of 50-70 min compares well with data from photodegradation experiments in organic liquids, but is much shorter than half-lives observed in studies with soil and sediments using thicker layers. We believe that the limited penetration of light into thick soil and sediment layers as used in other studies is the main reason for the observed differences. As other authors have reported before $\left(\right.$ e.g. $\left.{ }^{[36]}\right)$, we also observed an intermediate formation of brominated dibenzofurans, which are known to possess a high toxic potency. 


\section{Implications}

Our analytical data show that DecaBDE, PentaBDE and HBCD are ubiquitous in the Swiss environment, whereas TBBPA was only found occasionally. We have not found evidence for large individual point sources of DecaBDE, PentaBDE and HB$\mathrm{CD}$; instead our data indicate that there are many diffuse sources of these compounds in Switzerland and that many stages of their life cycles may lead to emissions into the environment. Our data also clearly show that the atmosphere plays a key role in regional and supra-regional transport of these compounds, i.e. within urban areas but also to remote sites such as the Alps.

International research efforts have led to significant progress in the toxicological information on BFR within the past seven years. On the basis of these data, the members of the consensus platform on BFR within the NRP50 programme ${ }^{[37]}$ agreed that

i) PentaBDE is an endocrine disruptor,

ii) TBBPA and HBCD are potential endocrine disruptors, and

iii) no evidence exists for endocrine effects of DecaBDE.

For DecaBDE as well as for HBCD and PentaBDE, other toxic effects were observed, especially neurotoxicity and developmental toxicity. ${ }^{[3,38]}$ However, current exposure levels in Switzerland of the investigated BFR are below concentrations that have been shown to cause negative health effects. PentaBDE possesses an observed adverse effect level (NOAEL) in the range of 10-1000 $\mu \mathrm{g} \mathrm{kg}^{-1} \mathrm{~d}^{-1}$ in rats and mice. ${ }^{[3,39,40]}$ These values are clearly above the human uptake of BFR, which can be estimated from our data. This may be different for North America, where exposure levels are generally one to two orders of magnitude higher than in Europe. This shows that the anticipated ban of PentaBDE and the related phase-out of PentaBDE in Europe did indeed help to reduce the exposure of consumers in European countries including Switzerland. There is also no immediate health risk in Switzerland with regard to DecaBDE, HBCD and TBBPA, for which a lower toxicity has been reported ${ }^{[3,40]}$ than for PentaBDE and for which exposure is similar or smaller than for PentaBDE. The consensus platform on BFR agreed that TBBPA used as reactive additive in epoxy resins does not pose any risk at the moment. For HBCD and DecaBDE there is presently no risk. However, rising environmental concentrations (HBCD and DecaBDE), environmental persistence (HBCD and DecaBDE), bioaccumulation (HBCD) and slow transformation into harmful compounds (DecaBDE) lead to the conclusion that industry is urged to seek for environmentally friendly alternatives for these two compounds.

\section{Acknowledgements}

Many people contributed to these studies and we are thankful to all of them, especially to our colleagues at Empa: Myriam Bergman, Erika Gujer, Regula Haag, Saverio Iozza, Michael Naef, Cornelia Seiler, Heinz Vonmont, Daniela Wenger and Max Wolfensberger; to colleagues and partners within NRP50: all members of the steering committee for their continuous support and advice; Walter Giger, Paul Hartmann, Hans-Peter E. Kohler, Michael Sturm and Etienne Vermeirssen from Eawag; Andreas Buser and Leo Morf from Geopartner; Markus Bläuenstein, Konrad Hungerbühler and Martin Scheringer from ETHZ; Daniel Bernet and Helmut Segner from the University of Bern; Markus Zeh, Daniel Scheidegger and Ueli Ochsenbein from the Canton of Bern, Patricia Holm from the University of Basel and many more.

Received: March 22, 2008

[1] M. Alaee, P. Arias, A. Sjödin, A. Bergman, Environment International 2003, 29, 683 .

[2] U. Örn, A. Bergman, Proceedings of BFR 2004, p. 467.

[3] L. S. Birnbaum, D. F. Staskal, Environ Health Perspect. 2004, 112, 9.

[4] M. J. LaGuardia, R. C. Hale, E. Harvey, Environ. Sci. Technol. 2006, 40, 6247.

[5] R. J. Law, M. Kohler, N. V. Heeb, A. C. Gerecke, P. Schmid, S. Voorspoels, A. Covaci, G. Becher, K. Janak, C. Thomsen, Environ. Sci. Technol. 2005, 39, 281A.

[6] N. V. Heeb, W. B. Schweizer, P. Mattrel, R. Haag, A. C. Gerecke, M. Kohler, P. Schmid, M. Zennegg, M. Wolfensberger, Chemosphere 2007, 68, 940.

[7] N. V. Heeb, W. B. Schweizer, M. Kohler, A. C. Gerecke, Chemosphere 2005, 61, 65.

[8] N. V. Heeb, W. B. Schweizer, P. Mattrel, R. Haag, M. Kohler, Chemosphere 2007, 66, 1590 .

[9] A. C. Gerecke, M. Kohler, M. Zennegg, P. Schmid, N. Heeb, Organohalogen Compounds 2003, 61, 155.

[10] A. Covaci, A. C. Gerecke, R. J. Law, S Voorspoels, M. Kohler, N. V. Heeb, H Leslie, C. R. Allchin, J. deBoer, Environ. Sci. Technol. 2006, 40, 3679.

[11] M. Zennegg, M. Kohler, A. C. Gerecke, P Schmid, Chemosphere 2003, 51, 545.

[12] P. Schmid, M. Kohler, E. Gujer, M Zennegg, M. Lanfranchi, Chemosphere 2007, 67, 16.

[13] M. Kohler, P. Schmid, E. Gujer, A. C. Gerecke, M. Zennegg, N. V. Heeb, H Naegeli, Proceedings of Setac Europe, Prague, 2004

[14] M. Kohler, M. Zennegg, C. Bogdal, A. C. Gerecke, P. Schmid, N. V. Heeb, M. Sturm, H. Vonmont, H.-P. E. Kohler, W. Giger, Environ. Sci. Technol. 2008, in press.

[15] M. Kohler, M. Zennegg, A. C. Gerecke, P. Schmid, N. Heeb, Organohalogen Compounds 2003, 61, 123 .
[16] A. C. Gerecke, P. C. Hartmann, N. V. Heeb, H. P. Kohler, W. Giger, P. Schmid, M. Zennegg, M. Kohler, Environ. Sci. Technol. 2005, 39, 1078.

[17] A. C. Gerecke, Organohalogen Compounds 2006, 68, 1978 .

[18] P. C. Hartmann, P. Burkhardt-Holm, W. Giger, Environmental Pollution 2007, 146, 107.

[19] P. Schmid, E. Gujer, M. Zennegg, M. Lanfranchi, Organohalogen Compounds 2004, 66, 1716.

[20] C. Naert, C. Van Peteghem, J. Kupper, L. Jenni, H. Naegeli, Chemosphere 2007, 68 977.

[21] A. C. Gerecke, W. Giger, P. C. Hartmann, N. V. Heeb, H.-P. E. Kohler, P. Schmid, M. Zennegg, M. Kohler, Chemosphere 2006 64, 311.

[22] R. C. Brändli, T. Kupper, T. D. Bucheli, M. Zennegg, S. Huber, D. Ortelli, J. Müller, C. Schaffner, S. Iozza, P. Schmid, U. Berger, P. Edder, M. Oehme, F. X. Stadelmann, J. Tarradellas, J. Environ. Monit. 2007, 9, 465.

[23] T. Kupper, L. F. de Alencastro, R. Gatsigazi, R. Furrer, D. Grandjean, J. Tarradellas, Chemosphere, 2008, 71 , 1173

[24] C. Bogdal, M. Kohler, P. Schmid, M. Scheringer, K. Hungerbühler, Organohalogen Compounds 2007, 69, 441.

[25] R. A. Hites, Environ. Sci. Technol. 2004 38,945 .

[26] C. A. de Wit, Chemosphere 2002, 46 , 583.

[27] S. Voorspoels, A. Covaci, P. Lepom, S Escutenaire, P. Schepens, Environ. Sci. Technol. 2006, 40, 2937.

[28] B. Gomara, L. Herrero, J. J. Ramos, J. R. Mateo, M. A. Fernandez, J. F. Garcia, M J. Gonzalez, Environ. Sci. Technol. 2007, 41,6961 .

[29] S. Harrad, S. Hazrati, C. Ibarra, Environ. Sci. Technol. 2006, 40, 4633 .

[30] USEPA, Washington, DC, National Center for Environmental Assessment, 1997.

[31] S. Voorspoels, A. Covaci, H. Neels, P. Schepens, Environment International 2007, 33, 93.

[32] A. C. Gerecke, Proceedings of BFR 2007, Amsterdam, 2007.

[33] M. Zennegg, M. Kohler, P. C. Hartmann, M. Sturm, E. Gujer, P. Schmid, A. C. Gerecke, N. V. Heeb, H.-P. E. Kohler, W. Giger, Chemosphere 2007, 67, 1754

[34] A. M. Buser, L. S. Morf, R. Taverna, H. P. Bader, R. Scheidegger, Organohalogen Compounds 2007, 69, 2748.

[35] L. S. Morf, A. M. Buser, R. Taverna, H.-P. Bader, R. Scheidegger, Chimia 2008, 62, 424.

[36] I. Watanabe, R. Tatsukawa, Bull. Environ. Contam. Toxicol. 1987, 39, 953.

[37] M. Trachsel, Chimia 2008, 62, 432.

[38] H. Viberg, A. Fredriksson, E. Jakobsson, U. Orn, P. Eriksson, Toxicol. Sci. 2003 , 76,112 .

[39] S. N. Kuriyama, C. E. Talsness, K. Grote, I. Chahoud, Environ. Health Perspect. $\mathbf{2 0 0 5}, 113,149$

[40] P. O. Darnerud, Environment International 2003, 29, 841 